\title{
ANDROCENTRISMO, A CONSTRUÇÃO DA DOMINAÇÃO CULTURAL MASCULINA
}

\author{
*Dulcilene Ribeiro Soares Nascimento
}

\section{RESUMO}

Os discursos acadêmicos atualmente estão deveras voltados no sentido da desconstrução e superação dos preconceitos e discriminações produzidos ao longo da história pela sociedade .Em meio a tantos temas que pulsam pela revisão histórica está o Androcentrismo em toda sua extensão e alcance na sociedade pressionado pelo crescente debate em torno da temática dos gêneros e principalmente no sentido de conscientizar as gerações vindouras para a erradicação dos "centrismos" que dividem e desagregam os valores humanos.

Palavras-Chave: Androcentrismo, Desconstrução, Gêneros, Sociedade.

\section{ABSTRACT}

The academic speeches currently indeed are come back in the direction of the desconstruction and overcoming of the preconceptions and discriminations produced throughout history for the society. In way to as many subjects that they beat for the historical revision it is the Androcentrism in all its extension and reach in the society pressured for the increasing debate around the thematic one of the genres and mainly in the direction to acquire knowledge the coming generations for the eradication of the "centrisms" that divide and disaggregate the human values.

Word-Key: Androcentrism, Desconstruction, Genres, Society. 
RESUMEN: Los discursos académicos se centran actualmente en la deconstrucción y superación de prejuicios y discriminación producidos a lo largo de la historia por la sociedad. En medio de tantos temas que palpitan a través de la revisión histórica, el androcentrismo en toda su extensión y alcance en la sociedad presionado por creciente debate sobre el tema de los géneros y principalmente en el sentido de sensibilizar a las generaciones futuras sobre la erradicación de los "centrismos" que dividen y desagregan los valores humanos.

Palabras clave: Androcentrismo, Deconstrucción, Géneros, Sociedad.

* Dulcilene Ribeiro Soares Nascimento é PHD e Doutora em História, Mestre em Ciência Política, Cidadania e Governação, Mestre em Educação, Especialista em Metodologia do Ensino, Pesquisa com extensão em Educação e Licenciada em História.

\section{INTRODUÇÂO}

Ao abordar gênero como uma construção histórica, social, política e cultural, considera-se que as relações sociais estabelecidas e os papéis atribuídos a homens e mulheres são formados, instituindo diferenças que geralmente são classificatórias, deixando sua marca em cada momento histórico.

Esse debate torna-se ainda mais amplo quando se trata dessas representações sociais em meio ao campo das práticas pedagógicas. (De acordo com França (2011, p. 302)) [...] acreditarmos que nossa identidade de gênero e sexual é construída de maneira hierárquica e são pequenos gestos e atitudes cotidianas que reforçam esta hierarquia como hegemônica e natural. A tendência quase universal de se reduzir a raça humana ao termo "o homem" é um exemplo excludente que ilustra um comportamento androcêntrico.

Nesse sentido toda a construção hierárquica tem historicamente na maioria das sociedades, o homem enquanto ponto de referência. Surgem assim os “centrismos' que como o próprio termo induz trata-se de exageros em termos de idéias e comportamentos que geram fanatismos e divergências. 
Meninas e meninos adquirem características e atribuições aos apreciados papeis femininos e masculinos. "São levadas (os) a se identificarem com padrões do que é feminino e masculino para em seguida, melhor realizarem estes papeis" (ARAÚJO, OLIVEIRA, ALMEIDA, 2009, p. 3).

\section{ANDROCENTRISMO ENQUANTO CONSTRUÇÃO SÓCIO- HISTÓRICA}

$\mathrm{O}$ androcentrismo é um termo cunhado pelo sociólogo americano Lester $\mathrm{F}$. Ward (SOUZA, 2009) que diz respeito às perspectivas que levam em consideração o homem como foco de análise do todo. Está literalmente ligado à noção de patriarcado. Ressalta-se aqui que não se circunscreve apenas ao privilégio dos homens, mas também à forma com a qual as experiências masculinas são consideradas como as experiências de todos os seres humanos e tidas como uma norma universal, tanto para homens quanto para mulheres, sem dar o reconhecimento completo e igualitário à experiência feminina. É também chamada de sociedades falocêntricas aquelas que assim se moldam.

Mesmo com a alteração nos padrões sociais, políticos, econômicos e culturais atuais e tendo em vista a forma como as famílias se configuram com a diversificação dos papéis de homens e mulheres, a sociedade ainda se pauta no modelo androcêntrico. Nesse ínterim mais do que nunca as discussões acerca da temática do gênero no sentido de equiparação de papéis e de valores sociais entre os sexos se faz mais do nunca presente e necessário.

Historicamente a mulher passou a ter maior visibilidade e reversão do seu papel sexual devido às condições sociais, políticas e econômicas delineadas a partir da Revolução Industrial, e reforçados pelo feminismo ascendente na década de 60, Ainda que fruto de todo um processo histórico iniciado pelas mulheres camponesas e trabalhadoras que exerciam suas tarefas fora de casa, segundo Louro (1997), no entanto, [...] eram quase sempre (como são ainda hoje, em boa parte) rigidamente controladas e dirigidas por homens e geralmente representadas como secundárias, "de apoio", de assessoria ou auxílio, muitas vezes ligadas à assistência, ao cuidado ou à educação (LOURO, 1997, p. 17, grifos da autora). 
A este respeito, Hall (2005) salienta que o feminismo foi um movimento especialmente único no desencadeamento do processo de desestabilização nas relações entre gêneros, pois o questionamento e a contestação possibilitaram a politização de arenas inteiramente novas de vida social, promovendo a simetria social entre os gêneros requerida pelas mulheres.

Assim como a mulher, as famílias mudam ao longo dos ciclos de vida de seus membros e, por razões históricas e culturais, diferentes maneiras de vida familiar se desenvolveram e se desenvolvem, fazendo com que o termo "família" seja agora utilizado para descrever arranjos domésticos diversos daqueles que eram, em um dado momento, a "norma" (WEEKS, 2007).

Não são, portanto, as características biológicas que definem a distinção que se faz entre homens e mulheres, mas sim "[...] o que socialmente se construiu sobre os sexos [...]." (LOURO, 1997, p. 21), construção esta que deve ser observada para que se compreenda o lugar e as relações que se estabelecem entre homens e mulheres.

Ao se falar sobre gênero, um dos termos principais deste artigo, não tem-se a pretensão de negar a natureza biológica das identidades sexuais e de gênero, mas enfatiza-se, deliberadamente, o seu caráter de construção sócio-histórica sobre as características biológicas dos sujeitos, concebe-se gênero como constituinte da identidade dos sujeitos, transcendendo, como declara Louro (1997, p. 25), "[...] o mero desempenho de papeis.".

Ainda que com significativas mudanças no campo acadêmico, onde as mulheres possuem espaço abrangente e considerável, o teor da história educacional, é amplamente androcêntrico e isso se percebe nas produções científicas, no acesso enfim, ainda que com significativa participação, o domínio continua singularmente marcado pelo universo masculino.

Os Estudos Culturais e principalmente a abordagem multiculturalista e multirreferencial que se fortaleceram a partir da década de 80 ajudaram não somente a modificar os conceitos no campo do senso-comum, como também se modificaram tais conceitos dentro do campo acadêmico: estudos que dizem respeito às mulheres começaram a ser discutidos, levando a uma produção elevada de trabalhos sobre o assunto. Tais trabalhos tiveram como referência os estudos multiculturais, objetivando problematizar a cultura tomada como natural, procurando percebê-la como histórico-cultural. 
Como aponta Silva (2004), os Estudos Culturais preocupam-se com questões como cultura, significação, identidade e poder, todas conectadas entre si buscando a desconstrução do processo de naturalização que se formalizou na sociedade e propiciando um olhar crítico às narrativas e ações cotidianas dos sujeitos.

Ao se falar sobre gênero, tratamos também de relações de poder, de teorizações políticas que em si carregam concepções, representações, interpretações, perspectivas, justamente o que se procura relatar nesta análise (SILVA, 2004). Tal organização não almeja apresentar a constituição de categorias fixas de análise, mas, pelo contrário, pretende evidenciar as narrativas dos sujeitos participantes da pesquisa e problematizar conceitos e ações que nos parecem naturais.

\section{ANDROCENTRISMO, GÊNERO E ESCOLA}

Importante ressaltar que por se tratar de uma construção social, o gênero, carrega inúmeras composições e atribuições impostas e hierarquizadas. $O$ feminino e o masculino estão carregados de estereótipos e imposições a serem seguidas e são esses estereótipos que são percebidos tanto nas falas e nas atitudes das pessoas em seus diversos meios de convívio social.

Produto de uma análise teórica no que diz respeito à mulher e ao seu papel em meio à sociedade atual, papel este que foi durante muito tempo discriminado, silenciado e discutido a partir do prisma androcêntrico. Desta forma, a mulher como ser humano tendeu a ser ocultada durante a história em detrimento da cultura e do poder em que se encontrava inserida.

Um dos locais mais significativos para que essas categorias apareçam é na escola. Nesse lócus, tanto educadores quanto alunos e alunas desde muito cedo buscam se enquadrar nos padrões socialmente estabelecidos e que são reforçados a todo o momento em casa, na escola e por meio da mídia.

Segundo Louro (2003), Braga (2010), as escolas apresentam grande dificuldade em abordar esta temática, ainda que não seja a única responsável pelas questões relacionadas ao sexo e a sexualidade, é nela onde circulam os saberes 
sobre o corpo e a sexualidade. Os educadores atuam de maneira significativa neste processo de aquisição de conhecimento podendo influenciar seja com suas palavras, seja com sua omissão e silêncio. Um dos maiores problemas aqui enfrentados é a omissão por não saber agir com as situações que se apresentam ou agir preconceituosamente e estereotipadamente.

Atualmente, a dificuldade no âmbito escolar não é abordar essa história, mas problematizá-la e trabalhá-la de forma crítica, considerando que a opressão de mulheres e o estereótipo de família concebido não é algo que se configura como natural, mas uma "assimilação" resultante de um processo sócio-histórico-cultural. Passível, portanto, de desestabilização e transformação.

\section{CONSIDERAÇÔES FINAIS}

Os Estudos Culturais, de acordo a ótica de Giroux (1995), são os instrumentos que podem oferecer possibilidades aos/às educadores/as de reflexão sobre a teoria e prática educacionais e sobre o significado de educar os/as futuros/as profissionais da escola, de forma a atender as novas demandas sociais que, cada vez mais, afetam o cotidiano escolar.

Sua intenção segundo o autor é "[...] a tentativa para produzir novas metodologias e novos modelos teóricos para analisar a produção, a estrutura e a troca de conhecimentos." (GIROUX, 1995, p. 90-91,) e sobretudo propiciar aparato que possibilite a modificação de atitudes e hábitos que levem a reconsideração desse olhar androcêntrico e sobretudo da atitude androcêntrica da sociedade.

A escola possui papel importante nesse processo de desconstrução de visões e de discursos andorocêtricos, visto que a sociedade não comporta mais e a cada dia dá nitidamente os sinais de desgaste frente as atitudes consideradas excludentes, maniqueístas que proliferam qualquer tipo de intolerância. 


\section{REFERENCIAS}

HALL, Stuart. A Identidade Cultural na Pós-Modernidade. Tradução de: Tomas Tadeu da Silva e Guacira Lopes Louro. 10ª ed. Rio de Janeiro: DP\&A, 2005.

LOURO, Guacira Lopes. Gênero, sexualidade e educação: Uma perspectiva pós-estruturalista. Petrópolis, RJ: Vozes, 1997.

. Pedagogias da sexualidade. In: LOURO, G. L. (Org.). O corpo educado. Belo Horizonte: Autêntica, 2007. p. 7-34.

Currículo, gênero e sexualidade. In: LOURO, Guacira Lopes (Org.); FELIPE, Jane (Org.); GOELLNER, Silvana (Org.). Corpo, gênero e sexualidade. Um debate contemporâneo na Educação. 6 ed. Petrópolis: Vozes, 2010.

SILVA, Tomaz Tadeu da (org.). Alienígenas na sala de aula: uma introdução aos estudos culturais em educação. Tradução de Tomaz Tadeu da Silva. Petrópolis, RJ: Vozes, 1995.

Documentos de Identidade - Uma introdução às teorias do currículo. Belo Horizonte: Autêntica, 2004.

SOUZA, R. F. Androcentrismo. Disponível em: <http://www.artigos.com/artigos/humanas/sociologia/androcentrismo-6724/artigo/>. Acesso em 16.08.2012.

WEEKS, Jeffrey. O corpo e a sexualidade. In: LOURO. G. L. (Org.). O corpo educado: pedagogias da sexualidade. Belo Horizonte: Autêntica, 2007. p. 7-34. 